\title{
Realisasi Bantuan Alat Mesin Pertanian Kepada Subak (Kasus Pelaksanaan Program Upaya Khusus Peningkatan Produksi Padi Jagung dan Kedelai di Subak Penginyahan Desa Puhu Kecamatan Payangan Kabupaten Gianyar)
}

\author{
I NYOMAN USADI PRADNYANA, I DEWA PUTU OKA SUARDI, \\ A.A.A WULANDIRA SAWITRI DJELANTIK
}

\author{
Program Studi Agribisnis Fakultas Pertanian Universitas Udayana \\ Jalan P.B. Sudirman Denpasar 80232 \\ Email: usadipradnya@gmail.com \\ okasuardi@unud.ac.id
}

\begin{abstract}
The Realization of Agricultural Machinery Aid To Subak (Implementation Case of Special Effort Program Enhancement of Rice Corn and Soybeans Production in Subak Penginyahan, Puhu Village of Payangan District, Gianyar)
\end{abstract}

Indonesia is one of agricultural country and most of the citizen work in agriculture sector but in some recent years Indonesia always import food from other countries, to prevent this from happening continuously in 2015, the government makes a special effort progarm (Upsus) enhancement of rice, corn, and soybeans production in 2017 is expected that Indonesia has reached food self-sufficiency, Upsus program has some kind of aids like agricultural equipment and machine aid (Alsintan) that is expected to simplify and speed up the production process. This study aims to find out (1) To find out the suitability of the proposed agricultural machinery aid (Alsintan) proposed by Subak Penginyahan; (2) To find out the use of agricultural machinery which is Subak Penginyahan recieved.The location of this research is located in Subak Penginyahan, Puhu Village, Payangan District, Gianyar Regency. Population of this research is 70 active members of Subak Penginyahan. Sample size was determined using Nottoadmojo formula, so the number of respondents who were taken 41 people and added with 1 respondent from Agriculture Department of Gianyar Regency, 1 PPL respondent who in charge at Penginyahan Subak and 1 respondent from Pekaseh Subak Penginyahan.The result of this study indicates that the realization of Alsintan aid in Subak Penginyahan is not suitable as purposed. There are differences in numbers and types of Alsintan that is proposed with received by Subak. For Alsintan type received by Subak is alsintan hand tractor type with this the realization of Alsintan aid that is purposed by Subak is suitable with what is proposed by Subak. Based on findings of the research that the writer conducted, it can be suggested to the government to increase its attention to the farmer continuously; In this case to continue aids provision that could help and provoke the enthusiasm of farmers to farm.

Keywords: realization, alsintan, Upsus program, Subak 


\section{Pendahuluan}

\subsection{Latar Belakang}

Indonesia adalah salah satu negara yang kaya akan sumber daya alam. Ini terbukti dengan keadaan tanah Indonesia yang sangat subur hingga mendapatkan perumpamaan biji yang tak sengaja jatuhpun akan segera tumbuh dengan alaminya.Dengan kekayaan alam yang dimiliki Indonesia, tidak heran menjadikannya sebagai salah satu negara yan memiliki peran penting sebagai produsen bahan pangan di mata dunia.Indonesia, apapun bisa tumbuh dan berkembang. Apalagi kalau membahas masalah pangan, Indonesia hampir memiliki segala jenis bentuk pangan. Namun, meskipun Indonesia menduduki posisi ketiga sebagai negara penghasil pangan di dunia, hampir setiap tahun Indonesia selalu saja menghadapi masalah yang sama yaitu mengimpor bahan pangan dari negara lain. (Permentan, 2015).

Tahun ke tahun jumlah penduduk di Indonesia terus mengalami pertumbuhan, ini dikarenakan angka kelahiran lebih besar dibandingkan angka kematian. Sebagian besar penduduk Indonesia mengkonsumsi beras. Karena beras sudah menjadi makanan pokok yang tidak mudah digantikan dengan bahan pangan yang lainnya. Indonesia termasuk dalam lima negara dengan jumlah penduduk terbesar di dunia.

Kementerian Pertanian telah menetapkan upaya khusus pencapaian swasembada berkelanjutan padi dan jagung serta swasembada kedelai melalui kegiatan rehabilitasi jaringan irigasi tersier dan kegiatan pendukung lainnya, antara lain, pengembangan jaringan irigasi, optimasi lahan, pengembangan system of rice intensification (SRI), Gerakan Pengolahan Tanaman Terpadu (GP-PTT), Optimasi Perluasan Areal Tanam Kedelai melalui Peningkatan Indeks Pertanaman (PAT-PIP Kedelai), Perluasan Areal Tanaman Jagung (PAT Jagung), Penyedian Sarana dan Prasarana Pertanian (benih, pupuk, pestisida, alat dan mesin pertanian), Pngendalian OPT dan Dampak perubahan iklim, Asuransi Pertanian dan Pengawasan/Pendampingan. (Kementan, 2015).

Subak Penginyahan yang terletak di Desa Puhu Kecamatan Penginyahan Kabupaten Gianyar masuk kedalam salah satu subak yang mendukung program swasembada pangan dalam program Upsus (Upaya Khusus) peningkatan produksi padi, jagung dan kedelai. Subak Penginyahan memiliki luas lahan 57 ha namun dalam pengolahan lahan tersebut Subak Penginyahan membutuhkan bantuan alat mesin pertanian sementara dismping itu alat mesin pertanian di subak belum tersedia. Pada tahun 2015 Subak Penginyah telah mengusulkan bantuan alat mesin pertanian pada program Upsus Pajale berupa traktor dan power thresher.

\subsection{Tujuan Penelitian}

Sejalan dengan permasalahan yang telah dirumuskan, maka tujuan dari penelitian ini untuk: (1) untuk mengetahui kesesuaian usulan bantuan alat mesin pertanian (Alsintan) yang diusulkan oleh Subak Penginyahan; (2) untuk mengetahui pengoperasian alat mesin pertanian yang diterima Subak Penginyahan. 


\section{Metode Penelitian}

\subsection{Lokasi dan Waktu Penelitian}

Lokasi penelitian di Subak Penginyahan, Desa Puhu, Kecamatan Payangan, Kabupaten Gianyar (Anonim, 2015).Waktu pengumpulan data berlangsung dari bulan Oktober sampai dengan Desember 2016.

\subsection{Penentuan Populasi dan Responden}

Populasi dalam penelitian ini adalah semua anggota aktif dari Subak Penginyahanyang berjumlah 70orang.Penentuan jumlah responden petani,berpedoman kepada pendapat Notoatmojo(2005) dari jumlah keseluruhan responden dalam penelitian ini adalah 44 orang yang terdiri dari 41 responden petani ditambahsatu orang dari pengurus subak yaitu pekaseh, satu orang PPL dan satu orang dari Dinas Pertanian dan Perkebunan Kabupaten Gianyar.

\subsection{Metode Pengumpulan Data, Instrumen Pengumpulan Data, dan Metode Analisis}

Teknik pengumpulan data yang digunakan yaitu wawancara, wawancara mendalamdan dokumentasi. Wawancara adalah metode pengumpulan data dengan tanya jawab secara sistematis berlandaskan pada tujuan penelitian Lerbin, 1992 (dalam Hadi, 2007). Dokumentasi dilakukan dengan mengambil gambar tentang hasil realisasi alat mesin pertanian di Subak Penginyahan.Instrumen pengumpulan data berupa kuesioner, dimana diajukan pertanyaan tertulis kepada responden untuk mendapatkan informasi yang diperlukandalam penelitian(Mardalis, 2008).Variabel utama peneliti meliputi, alat mesin yang diterima dan yang diusulkan, pengoperasian alat mesin pertanian yang diterima.Metode analisis yang digunakan adalah deskriptif kualitatif (Moleong, 2011).

\section{Hasil dan Pembahasan}

\subsection{Karakteristik responden}

Karakteristik responden dalam penelitian ini meliputi umur, tingkat pendidikan formal, jenis pekerjaan, jumlah anggota rumah tangga, dan luas lahan garapan (Sugiyono, 2005).

\subsubsection{Umur}

Usia adalah umur individu yang terhitung mulai saat dilahirkan sampai berulang tahun (Elisabeth B.H, 1997). Hasil dari penelitian menjukan bahwa rata-rata umur responden 54,32 tahun dengan kisaran dari 37 tahun s.d 75 tahun. Sebanyak 33 orang $(80,49 \%)$ petani termasuk dalam kategori produktif, sedangkan delapan orang $(19,51 \%)$ petani termasuk dalam kategori non-produktif. Hal ini berarti bahwa responden mampu dan dapat menerima informasi baru dan inovasi dalam memperbaiki usahataninya, dalam hal ini tentang realisasi bantuan alat mesin pertanian, sehingga dapat mempermudah dan mempercepat dalam pengolahan tanah. 


\subsubsection{Tingkat pendidikan formal}

Distribusi responden berdasarkan tingkat pendidikan formal dibedakan atas tidak tamat SD, tamat SD, tamat SMP, tamat SMA, dan Sarjana / Perguruan Tinggi. Tingkat pendidikan digunakan sebagai salah satu indikator guna menggambarkan seberapa besar tingkat penerimaan informasi yang dimiliki oleh responden.

Tingkat pendidikan yang memadai membuat petani akan semakin mengerti dan memahami materi-materi yang disampaikan oleh penyuluh serta mempengaruhi kemampuan petani untuk menerima inovasi baru (Thoha, 2004). Berdasarkan hasil penelitian pada responden petani dan pekaseh, dapat dijelaskan bahwa tingkat pendidikan formal responden Subak Penginyahan masih tergolong tinggi, hal ini dapat dilihat dari pendidikan yang dikenyam tiga orang sarjana $(7,32 \%)$ dan 10 orang $(39,02 \%)$ adalah SMA sedangkan hanya empat orang $(9,76 \%)$ responden yang tidak tamat pendidikan SD. Responden dengan tingkat pendidikan tamat SD sebanyak delapan orang $\left(19^{\prime} 51 \%\right)$ dan responden dengan tingkat pendidikan tamat SMP sebanyak 10 orang $(24,39 \%)$.

\subsubsection{Jenis pekerjaan}

Mata pencarian pokok terbanyak responden sebagai petani yaitu sebanyak 22 orang $(53,66 \%)$, dan 19 orang lainnya $(46,34 \%)$ memiliki pekerjaan pokok sebagai pedagang, pekerja bangunan, pengerajin dan Pegawai swasta. Pekerjaan sampingan yang dimiliki oleh responden sebagai petani sebanyak 19 orang $(79,16 \%)$ dan lima orang $(20,83 \%)$ sebagai pedagang dan pengerajin sisanya tidak memiliki pekerjaan sampingan.

\subsubsection{Jumlah anggota rumah tangga}

Berdasarkan hasil penelitian, rata-rata anggota rumah tangga responden adalah 4,73 orang yang terdapat pada kisaran jumlah tiga sampai tujuh orang. Sebanyak 82,93\%tergolong kedalam kelompok dengan anggota rumah tangga diantara tiga hingga lima orang dan hanya 17,07\% yang tergolong kedalam kelompok dengan anggota rumah tangga enam sampai dengan tujuh orang.

\subsubsection{Pemilikan dan penggunaan lahan}

Berdasarkan hasil penelitian rata-rata luas lahan sawah yang dimiliki responden seluas 28,90 are. Rata-rata luas lahan garapan responden seluas 55,80 are yang terdiri dari lahan milik seluas 25,85 are dan lahan nyakap seluas 29,95 are. Selain menyakap lahan milik petani lain, ada juga responden yang menyewakan lahanya ke petani lain seluas 3,05 are. Rata-rata luas lahan pekarangan yang dimiliki responden seluas 5,35 are dan lahan tersebut dikerjakan sendiri oleh pemiliknya dan tidak semua responden mengusahakan untuk tanaman pertanian, sebagian dimanfaatkan untuk pemukiman. Rata-rata luas lahan tegalan yang dimiliki responden seluas 25 are, yang ditanami jenis tanaman seperti kelapa, pepaya, pisang dan lain-lain. 


\subsubsection{Pekaseh}

Pekaseh di Subak Penginyahan bernama I Wayan Wirnada yang berusia 51 tahun dan menjabat sebagai pekaseh dari tahun 2007.I Wayan Wirnada memiliki seorang istri dan mempunyai tiga orang anak. Pekerjaan sehari-hari Bapak Wayan Wirnada adalah sebagai petani dengan luas garapan 90 are dan tidak memiliki pekerjaan sampingan.

\subsubsection{PPL}

Petugas PPL di Subak Penginyahan bernama BapakI Nyoman Mandra lahir pada tanggal 30 Desember 1957 yang saat ini berusia 60 tahun dan memiliki dua orang anak. Bapak Nyoman Mandra berasal dari Desa Melinggih, Kecamatan Payangan, Kabupaten Gianyar.Pendidikan terakhir Bapak Nyoman Mandra adalah SPMA.

\subsubsection{Pegawai Dinas Pertanian Kabupaten Gianyar}

Responden kuncidalam penelitian ini adalah Dewa Nyoman Rai staf pada Dinas Pertania, Perhutanan dan Perkebunan Kabupaten Gianyar golongan III/d yang memegang jabatan kasi pengembangan saprodi dan Alsintan.

Dewa Nyoman Rai berasal dari Desa Singakerta, Kecamatan Ubud lahir pada tanggal 29 Desember 1962, pendidikan terakhir adalah Sarjana Pertanian (S1) di Universitas Dwijendra pada 1984. Jumlah anggota keluarga Bapak Dewa Nyoman Rai berjumlah empat orang yang terdiri dari istri dan dua orang anak.

\subsection{Realisasi Bantuan Alat dan Mesin Pertanian Kepada Subak}

\subsubsection{Kondisi Ketersediaan Alat Mesin Pertanian}

Secara umum, ketersediaan alat mesin pertanian di Subak Penginyahan belum ada dan sangat membutuhkan bantuan Alsintan dalam hal proses pra panen dan pasca panen, ditambahkan juga oleh Pekaseh dan PPL Subak Penginyahanbahwa bantuan Alsintan berupa traktor dan power thresher sangat dibutuhkan oleh subak untuk efisiensi waktu, biaya dan tenaga untuk mempercepat proses pengolahan tanah dan proses panen. Menurut pegawai Dinas Pertanian dan Perkebunan Kabupaten Gianyar Dewa Nyoman Rai,S.P. Hasil dari verifikasi menunjukan Subak Penginyahan sangat memerlukan bantuan Alsintan karena di Subak Penginyahan tidak memiliki Alsintan hal ini akan berpengaruh pada pencapaian hasil yang ditargetkan oleh program Upsus Pajale.

\subsubsection{Usulan Bantuan dan Kesesuaian Bantuan a. Jumlah dan jenis Alsintan}

Realisasi bantuan alat mesin pertanian di Subak Penginyahan belum sesuai dengan apa yang diusulkan oleh subak. Hasil penelitian menunjukkan bahwa bantuan alat mesin pertanian yang diusulkan oleh Subak Penginyahan adalah satu unit traktor dan satu unit power thresher, namun dalam realisasinya bantuan alat mesin 
pertanian yang diterima oleh Subak Penginyahan hanya alat mesin pertanian berupa traktor. Sedangkan alat mesin pertanian berupa power thresherSubak Penginyahan tidak mendapatkannya karena hasil verifikasi dari tim Dinas Pertanian, Kehutanan dan Perkebunan Kabupaten Gianyar menunjukkan Subak Penginyahan dianggap belum begitu membutuhkan bantuan power thresher dibandingkan subak lain, selain itu keterbatasan jumlah bantuan power threshermenjadi salah satu faktor yang menyebakan Subak Penginyahan tidak meneriman bantuan power thresher.

\section{b. Jenis Alsintan}

Hasil penelitian menunjukkan bahwa realisasi jenis Alsintan yang diterima oleh Subak Penginyahan sudah sesuai dengan yang diusulkan.Pekaseh dan PPL menyatakan Alsintan yang diusulkan adalah traktor jenishand traktor, karena jenis traktor ini paling sesuai dengan kondisi lahan di Subak Penginyahan. Di samping itu di tambahkan oleh pegawaiDinas Pertanian Dewa Nyoman Rai, S.P bahwa hand traktor adalah jenis traktor yang paling sesuai dengan keadaan lahan persawahan di Bali terracesiring.

\subsubsection{Pengoperasian}

Subak Penginyahan yang mendapatkan bantuan Alsintan tidak menerima program pelatihan untuk pengoperasiannya, hal ini dikarenakan ketentuan dari program Upsus Pajale yang tidak mencantumkan adanya pelatihan pengoperasian Alsintan kepada anggota subak.Setiap subak yang menerima bantuan Alsintan diharapkan sudah memiliki anggota yang berkompeten dalam mengoperasikan bantuan tersebut.Pakeseh dan PPLmengharapkan untuk kedepannya dari pihak pemerintah memberikan pelatihan tentang pengoperasian Alsintan agar anggota subak dapat trampil dan berkompeten dalam mengoprasikan Alsintan yang diterima oleh subak.

\section{Simpuan dan Saran}

\subsection{Simpulan}

Berdasarkan hasil penelitian dapat disimpulkan sebagai berikut.

1. Realisasi bantuan Alsintan di Subak Penginyahan belum sesuai seperti yang diusulkan. Ada perbedaan jumlah dan jenis Alsintan yang diusulkan dengan yang diterima oleh subak, subak mengusulkan satu unit traktor dan satu unitpower thresher tetapi subak hanya menerima bantuan satu unit traktor saja alasan ketidak sesuain tersebut karena ketentuan dari program Upsus Pajale bahwa satu subak hanya bisa menerima satu jenis bantuan alat mesin pertanian.

2. Program Upsus tidak memberikan pelatihan pengoperasian Alsintan bagi subak yang mendapat bantuan. Dengan kata-kata lain Subak Penginyahan tidak menerima pelatihan pengoperasian alat mesin pertanian yang diterimanya. 


\subsection{Saran}

Berdasarkan temuan pada penelitian yang saya lakukan, dapat disarankan kepada pemerintah untuk memenuhi usulan bantuan jumlah dan jenis Alsintan yang diinginkan oleh subak dalam pemeberian program bantuan Upsus Pajale, dalam hal ini melanjutkan pemberian bantuan-bantuan lainya yang bisa membantu dan meningkatkan semangat petani untuk berusahatani.

Kepada pekaseh dan PPL diharapakan agar lebih aktif dalam mencari informasi tentang bantuan-bantuan Alsintan untuk mempermudah para anggota subak dalam berusaha tani sehingga mampu mengurangi biaya dalam berusahatani baik prapanen maupun pascapanen.

\section{Ucapan Terima Kasih}

Penulis menyampaikan terima kasih kepada seluruhkrama Subak Penginyahan, pekaseh, dan pegawaibidang saprodi dan Alsintan Dinas Pertanian Kabupaten Gianyar yang telah memberikan data penelitian dan semua pihak yang telah membantu dalam proses penyelesaian penelitian hingga termuat di e-jurnal.

\section{Daftar Pustaka}

Anonim, 2015 Profil Desa Puhu. Kecamatan Payangan: Gianyar.

Arikunto S, 2006. Prosedur Penelitian Suatu Pendekatan Praktik, Ed Revisi VI,Penerbit PT Rineka Cipta, Jakarta.

Elisabeth, B.H. 1997. Psikologi Perkembangan Suantu Pendekatan Sepanjang Rentang Kehidupan. Erlangga, Jakarta

Kementan, 2015. Kementan Pertanian Tahun 2015-2019. http://www.pertanian.go.id/file/RENSTRA_2015-2019.pdf. Diunduh pada tanggal 24 mei 2016.

Hadi.2007.Pengertian Wawancara.Ghalia.Jakarta

Mardalis. 2008. Metode Penelitian Suatu Pendekatan Proposal. PT. Bumi Aksar. Jakarta.

Moleong, Lexy J. 2011. Metodologi Penelitian Kualitatif. PT. Rosdakarya Offset. Bandung

Notoatmojo, S. 2005. Metodelogi Penelitian Kesehatan. Rineka Cipta. Jakarta

Permentan, 2015. Pedoman Pengawalan Penyuluh UPSUS. .http://www.pertanian.go.id/assets/upload/doc/PERMENTAN_PEDUM_UPSU S_APBNP.pdf. Diunduh 21 Desember 2015

Sugiyono, 2005, Metode Penelitian Kualitatif. Alfabeta. Bandung.

Thoha. 2004. Faktor yang Mempengaruhi Perkembangan Persepsi Seseorang. [Jurnal Online]. http://id.shvoong.com. Diunduh Tanggal 20 Desember 2015. 